Original Article

\title{
One-year longitudinal study on spinal kyphosis and respiratory function in community-dwelling older Japanese adults who require long-term care or support
}

\author{
Minami Sato, RPT ${ }^{1 *}$, Akihiro Yakabi, PhD, RPT ${ }^{2)}$, Yohei Sawaya, MSc, RPT ${ }^{1-3)}$, \\ Takahiro Shiba, RPT ${ }^{3)}$, Akira Kubo, PhD, RPT ${ }^{2)}$, Masahiro Ishizaka, PhD, RPT ${ }^{2}$, \\ TSUYOSHI HARA, PhD, RPT ${ }^{2}$ \\ 1) Division of Physical Therapy, Doctoral Program in Health Sciences, Graduate School of Health and \\ Welfare Sciences, International University of Health and Welfare: 2600-1 Kitakanemaru, Otawara-shi, \\ Tochigi 324-8501, Japan \\ 2) Department of Physical Therapy, School of Health Sciences, International University of Health and \\ Welfare, Japan \\ 3) Nishinasuno General Home Care Center, Department of Day Rehabilitation, Care Facility for the \\ Elderly "Maronie-en", Japan
}

\begin{abstract}
Purpose] To clarify the effects of longitudinal changes in older adults by evaluating the relationship between changes in spinal kyphosis and respiratory function over time in patients with certified need of care in the long-term care insurance system. [Participants and Methods] We included 57 older adults (28 males and 29 females) aged $\geq 65$ years who were identified as requiring long-term care or support. The participants were community-dwelling individuals undergoing ambulatory rehabilitation. We assessed the longitudinal changes in spinal kyphosis index, respiratory function and muscle strength, and body composition over 1 year. [Results] The spinal kyphosis index was 10.5 at the first measurement and 14.6 at 1 year after the first measurement, showing a significant increase. We did not detect any significant differences in respiratory function and muscle strength, or body composition. [Conclusion] This 1 year longitudinal comparison suggests that the spinal kyphosis indexes were high, and the respiratory function and trunk muscle mass remained unchanged. Therefore, the relationships were negligible.

Key words: Longitudinal change, Spinal kyphosis, Respiratory function
\end{abstract}

(This article was submitted Oct. 14, 2020, and was accepted Dec. 1, 2020)

\section{INTRODUCTION}

Spinal kyphosis is the most common postural alignment abnormality in the elderly. Previous studies have shown that its mechanisms of occurrence include weakening of the trunk extensor muscles with aging and osteoporosis and difficulty in moving the center of gravity backward ${ }^{1,2)}$. Adults with spinal kyphosis are at a high risk of falls, which not only contributes to postural and gait instability but also affects respiratory function ${ }^{3)}$. In particular, spinal kyphosis restricts thoracic movement during inspiration, leading to respiratory failure due to restricted ventilation ${ }^{4}$. In addition, spinal kyphosis creates difficulties in achieving extension of the thoracic spine during inspiration, which easily increases the load on the anterior thoracic and cervical muscles and hastens the onset of respiratory muscle failure ${ }^{5}$.

*Corresponding author. Minami Sato (E-mail: 1512047@g.iuhw.ac.jp)

(C2021 The Society of Physical Therapy Science. Published by IPEC Inc.

(c) (i) $(-)$ This is an open-access article distributed under the terms of the Creative Commons Attribution Non-Commercial No DerivaBY NG ND tives (by-nc-nd) License. (CC-BY-NC-ND 4.0: https://creativecommons.org/licenses/by-nc-nd/4.0/) 
The relationship between spinal kyphosis and respiratory function has been reported from various perspectives, but this relationship is unclear in older adults who are certified with long-term care insurance.

Several previous studies that compare the normal posture and kyphosis posture of young healthy people ${ }^{6,7)}$ and elderly people living in the community ${ }^{8}$ reported that the inspiratory function, respiratory muscle strength, and expiratory flow rate were significantly reduced in cases of severe spinal kyphosis. One study found a positive correlation between respiratory function and respiratory muscle strength when using the skeletal muscle mass index ${ }^{9}$. A longitudinal study of thoracic spine curvature and respiratory function in elderly people living in the community showed that females with more pronounced kyphosis had poorer respiratory function ${ }^{10)}$. Moreover, few studies have compared gender differences in spinal kyphosis in older adults certified with long-term care insurance. There are few studies on longitudinal changes in the progression of dorsal spine dysfunction and respiratory function in the elderly. The purpose of this study was to clarify the effects of longitudinal change in older adults certified with long-term care insurance by evaluating the relationship between spinal kyphosis and respiratory function over time.

\section{PARTICIPANTS AND METHODS}

We included 57 participants aged $\geq 65$ years (28 males and 29 females; age, $76.7 \pm 9.3$ years [mean \pm standard deviation]) who were identified as requiring long-term care or support. These participants were community-dwelling individuals who were undergoing ambulatory rehabilitation under the long-term care insurance system at least once a week. Their characteristics were as follows: height, $157.8 \pm 8.4 \mathrm{~cm}$; weight, $56.0 \pm 13.6 \mathrm{~kg}$; and body mass index, $22.3 \pm 4.2 \mathrm{~kg} / \mathrm{m}^{2}$. The participants were divided according to the certified level of long-term care or support that they required. The number of patients who required support levels 1 and 2 was 6 and 7, respectively ( 2 and 5 males and 4 and 2 females, respectively), whereas the number of patients who required care levels $1,2,3$, and 4 was $21,16,4$, and 3 , respectively $(9,7,3$, and 1 male and $12,8,1$, and 2 females, respectively).

This study was approved by the Ethics Review Committee of the International University of Health and Welfare (approval number, 17-Io-189-7) and was conducted in accordance with the Declaration of Helsinki. All participants or their families provided informed consent.

The degree of spinal kyphosis, respiratory function and muscle strength, and body composition were measured. For quantitative assessment of the degree of spinal kyphosis, the curvature between the seventh cervical vertebrae (C7) and the fourth lumbar vertebrae (L4) was traced using a free curve ruler (No. 971 65-50; Staedtler, Nuremberg, Germany). To measure the posture, the participant was placed in a comfortable sitting position with both feet on the ground. The shape of the curve was transcribed onto paper, and the length of the straight line connecting the C7 and L4 on the curve was defined as L (cm), the distance from the line to the apex of the curve was defined as $\mathrm{H}(\mathrm{cm})$, and the spinal kyphosis index was calculated using the technique described by Milne et $\mathrm{al}^{11)}$. This scale has been validated and is considered reliable ${ }^{11-13)}$, with higher values indicating greater kyphosis. There is no clear cutoff value; however, one study in the elderly defined spinal kyphosis as a spinal kyphosis index of $\geq 15^{8}$. We used the following parameters as measures of respiratory function: forced vital capacity (FVC), forced expiratory volume in 1 second (FEV1.0), percentage of the forced expiratory volume exhaled in 1 second (FEV1.0\%), and peak expiratory flow rate (PEFR). The following parameters were used as measures of respiratory muscle strength: maximum inspiratory pressure (PImax) and maximum expiratory pressure (PEmax). According to Black and Hyatt's method ${ }^{14)}$, maximum inhalation was performed from the residual volume and maximum expiration was performed from the total lung capacity. Pressure was maintained for 2 seconds through a nose grip and mouth filter. Inhalation and exhalation were defined as PImax and PEmax, respectively. An electronic diagnostic spirometer (Autospiro AS-507, Minato Medical Science Co., Ltd., Osaka, Japan) and a respiratory muscle strength meter (AAM377, Minato Medical Science Co., Ltd., Osaka, Japan) were used to measure the maximum values in accordance with the American Thoracic Society and European Respiratory Society guidelines ${ }^{15,16)}$. All measurements were performed with the patient in the sitting position.

For body composition, an InBody 520 (InBody, Tokyo, Japan) was used to measure the muscle mass of both the arms and legs; the trunk, skeletal muscle, and body fat masses; and the total body water. Statistical analyses were performed using paired t-tests for pre- and post-comparison of the spinal kyphosis index, respiratory function and muscle strength, and parameters for the body composition. We also used the unpaired t-test to compare gender differences in the spinal kyphosis indices. All statistical analyses were performed using SPSS Statistics version 25 (IBM, Armonk, NY, USA), and the significance level was set at $5 \%$.

\section{RESULTS}

Table 1 shows the characteristics of the participants and the results of the measurements, the results of the corresponding t-tests for the spinal kyphosis index, respiratory function and muscle strength, and items of the body composition. The spinal kyphosis index was 10.5 and 14.6 at the first measurement and 1 year after the first measurement, respectively, revealing a significant increase. Results of the respiratory function and muscle strength tests during the first measurement and 1 year after the first measurement were as follows: FVC, $2.0 \mathrm{~L}$ and 2.1 L; FEV1.0, 1.7 L and 1.7 L; FEV1.0\%, 83.7\% and 81.4\%; PEFR, 4.2 $\mathrm{L} / \mathrm{sec}$ and 3.9 L/sec; PImax, $31.2 \mathrm{cmH}_{2} \mathrm{O}$ and $35.8 \mathrm{cmH}_{2} \mathrm{O}$; and PEmax, $48.2 \mathrm{cmH}_{2} \mathrm{O}$ and $44.9 \mathrm{cmH}_{2} \mathrm{O}$, respectively; no 
Table 1. Characteristics and measurement results of the participants

\begin{tabular}{|c|c|c|c|c|c|c|}
\hline & \multicolumn{2}{|c|}{ The whole, $\mathrm{n}=57$} & \multicolumn{2}{|c|}{ Males, $\mathrm{n}=28$} & \multicolumn{2}{|c|}{ Females, n=29 } \\
\hline & First time & After one year & First time & After one year & First time & After one year \\
\hline \multicolumn{7}{|l|}{ Characteristics } \\
\hline Age (years) & $76.7 \pm 9.3$ & $77.7 \pm 9.3$ & $74.8 \pm 9.9$ & $75.8 \pm 9.9$ & $78.5 \pm 8.6$ & $79.5 \pm 8.6$ \\
\hline Height (cm) & $157.9 \pm 8.4$ & $157.9 \pm 8.4$ & $163.5 \pm 6.8$ & $163.5 \pm 6.8$ & $152.4 \pm 5.8$ & $152.4 \pm 5.8$ \\
\hline Weight (kg) & $56.0 \pm 13.0$ & $56.0 \pm 13.6$ & $62.3 \pm 13.1$ & $62.9 \pm 13.7$ & $50.0 \pm 9.7$ & $49.6 \pm 10.0$ \\
\hline BMI $\left(\mathrm{kg} / \mathrm{m}^{2}\right)$ & $22.3 \pm 4.0$ & $22.3 \pm 4.2$ & $23.2 \pm 3.8$ & $23.4 \pm 4.0$ & $21.5 \pm 4.0$ & $21.4 \pm 4.2$ \\
\hline \multicolumn{7}{|l|}{ Spinal kyphosis } \\
\hline Spinal kyphosis index & $10.5 \pm 3.3^{*}$ & $14.6 \pm 4.9^{*}$ & $11.2 \pm 3.5^{*}$ & $16.1 \pm 5.5^{*}$ & $9.8 \pm 3.1^{*}$ & $13.2 \pm 3.8^{*}$ \\
\hline \multicolumn{7}{|l|}{ Respiratory function } \\
\hline $\mathrm{FVC}(\mathrm{L})$ & $2.0 \pm 0.6$ & $2.1 \pm 0.7$ & $2.0 \pm 0.7$ & $2.6 \pm 0.6$ & $2.0 \pm 0.6$ & $1.7 \pm 0.4$ \\
\hline FEV1.0 (L) & $1.7 \pm 0.5$ & $1.7 \pm 0.6$ & $1.7 \pm 0.6$ & $2.1 \pm 0.6$ & $1.6 \pm 0.5$ & $1.4 \pm 0.4$ \\
\hline FEV1.0\%(\%) & $83.6 \pm 9.3$ & $81.4 \pm 10.5$ & $85.4 \pm 10.8$ & $80.8 \pm 10.8$ & $81.9 \pm 7.4$ & $82.0 \pm 10.4$ \\
\hline PEFR (L/sec) & $4.2 \pm 1.6$ & $3.9 \pm 1.8$ & $4.3 \pm 1.7$ & $4.8 \pm 1.8$ & $4.0 \pm 1.5$ & $3.1 \pm 1.3$ \\
\hline \multicolumn{7}{|l|}{ Respiratory muscle } \\
\hline $\operatorname{PImax}\left(\mathrm{cmH}_{2} \mathrm{O}\right)$ & $31.2 \pm 16.1$ & $35.8 \pm 16.6$ & $30.5 \pm 14.7$ & $36.9 \pm 14.6$ & $31.9 \pm 17.9$ & $34.7 \pm 18.7$ \\
\hline PEmax $\left(\mathrm{cmH}_{2} \mathrm{O}\right)$ & $48.2 \pm 22.8$ & $44.9 \pm 19.1$ & $54.0 \pm 20.7$ & $52.6 \pm 16.7$ & $42.8 \pm 23.9$ & $36.9 \pm 18.3$ \\
\hline \multicolumn{7}{|l|}{ Body composition } \\
\hline Limb muscle mass (kg) & $15.3 \pm 4.2$ & $15.2 \pm 4.8$ & $15.4 \pm 4.2$ & $15.9 \pm 4.2$ & $15.1 \pm 4.3$ & $14.3 \pm 5.4$ \\
\hline Trunk muscle mass (kg) & $17.4 \pm 3.8$ & $17.4 \pm 3.8$ & $17.4 \pm 3.8$ & $17.5 \pm 3.6$ & $17.3 \pm 3.9$ & $17.3 \pm 4.1$ \\
\hline Skeletal muscle mass (kg) & $20.5 \pm 4.7$ & $20.6 \pm 4.5$ & $20.7 \pm 4.8$ & $20.9 \pm 4.6$ & $20.4 \pm 4.6$ & $20.3 \pm 4.6$ \\
\hline Body fat mass (kg) & $17.1 \pm 8.9$ & $16.8 \pm 9.2$ & $18.0 \pm 11.0$ & $17.5 \pm 11.3$ & $16.2 \pm 6.1$ & $16.1 \pm 5.7$ \\
\hline Total body water (L) & $28.6 \pm 5.6$ & $29.1 \pm 5.9$ & $29.1 \pm 6.1$ & $29.5 \pm 6.0$ & $28.0 \pm 5.1$ & $28.6 \pm 5.9$ \\
\hline $\operatorname{SMI}\left(\mathrm{kg} / \mathrm{m}^{2}\right)$ & $6.1 \pm 1.1$ & $6.1 \pm 1.1$ & $6.1 \pm 1.1$ & $6.3 \pm 1.1$ & $6.0 \pm 1.1$ & $5.9 \pm 1.1$ \\
\hline
\end{tabular}

Mean \pm standard deviation. FVC: forced vital capacity; FEV1.0: forced expiratory volume in one second; FEV1.0\%: percentage of forced expiratory volume in one second; PEFR: peak expiratory flow; PImax: maximum inspiratory mouth pressure; PEmax: maximum expiratory mouth pressure, limb muscle mass: both arms muscle mass + both legs muscle mass; SMI: limb muscle mass/height $(\mathrm{m})^{2}$, paired t-tests $* \mathrm{p}<0.05$.

significant differences were detected. Additionally, no significant differences were detected in the changes in body composition from the first measurement to 1 year after the first measurement. The limb and trunk muscle masses were $15.3 \mathrm{~kg}$ and $15.2 \mathrm{~kg}$ and $17.4 \mathrm{~kg}$ and $17.4 \mathrm{~kg}$, respectively. Moreover, in all parameters, no significant differences were detected when males and females were compared.

\section{DISCUSSION}

Results showed that the spinal kyphosis index was higher 1 year later in the older adults certified with long-term care insurance. According to a previous study ${ }^{17}$ ), the common occurrence of spinal kyphosis in $20-40 \%$ of the elderly population is not only a problem caused by aging but also a major factor in the increase in physical dysfunctions such as impaired respiratory function, lower extremity muscle weakness, and loss of balance, as well as impairment of the activities of daily living (ADL) and, consequently, results in falls and spinal compression fractures, which ultimately lead to a lower quality of life and higher mortality rates. The causes of spinal kyphosis are multifactorial and include muscle weakness, spinal fractures, and degeneration of discs and ligaments. Of these causes, muscle weakness of the back muscles has been reported as the most likely cause of spinal kyphosis. However, in this study, there were no changes in the limb and trunk muscle masses, which suggests that the effect of muscle weakness was negligible.

In addition, a previous study ${ }^{18}$ ) found that the spinal kyphosis index was more related to the index of expiration than inhalation in males who were certified with long-term care insurance, while there was no relationship between the spinal kyphosis index and respiratory function in females who were certified with long-term care insurance. Therefore, it is thought that kinematic or anatomical characteristics may cause these gender differences. In this study, there were no apparent differences in the progression of spinal kyphosis and changes in respiratory function when the two genders were compared.

The participants were community-dwelling individuals undergoing ambulatory rehabilitation under the long-term care insurance system, and their respiratory function may have been maintained because of regular rehabilitation and increased opportunities to go out. Although no significant changes were observed in 1 year, there is a possibility that postural abnormalities such as spinal kyphosis may progress with long-term tracking. A study of community-dwelling older adults in their 
50 s to 80 s found that with increasing age in both males and females, a decline in the trunk extensor muscle group is associated with an increase in spinal kyphosis ${ }^{19}$. This may cause deformation of the thorax, decreased spinal mobility, and shortening of the abdominal muscle group, which may lead to decreased respiratory function. In addition, we would like to examine other factors such as comorbidities, pain, and decline in ADLs and would recommend the continued use of community-dwelling individuals undergoing ambulatory rehabilitation under the long-term care insurance system as the study population, in addition to spinal kyphosis as an outcome.

A limitation of this study is that it did not consider respiratory disease and medical history. In addition, it was measured at a single facility and age and care level were not standardized. Although the degree of spinal kyphosis was calculated using the spinal kyphosis index, it is possible to comprehensively evaluate the angles of the cervical, thoracic, and lumbar vertebrae using a spinal mouse and other techniques. Only thoracic spine kyphosis related to thoracic breathing is assessed, with the possibility of compensatory ventilation with abdominal breathing. This study only evaluated thoracic spine kyphosis; however, a comprehensive evaluation of the spine is needed. Although the instrument used for measurement was a spirometer, familiarity from repeated measurements and individual differences in the transmission of instructions may have influenced the results. In conclusion, this is the first study to reveal the longitudinal changes in spinal kyphosis and respiratory function in older adults certified with long-term care insurance.

\section{Funding and Conflict of interest}

The authors have no conflict of interests to declare as regards this research.

\section{REFERENCES}

1) Ostrakhovitch EA, Tabibzadeh S: Homocysteine and age-associated disorders. Ageing Res Rev, 2019, 49: 144-164. [Medline] [CrossRef]

2) Takai I, Miyano M, Nakai N, et al.: Postural change and posture control with aging. Japan Society of Physiological Anthropology, 2001, 6: 41-46.

3) Morifuji T, Shimada T, Sakamoto R, et al.: Relationship of spinal mobility in extension with balance and walking ability in patients with kyphosis. Rigakuryouhoukagaku, 2010, 25: 735-739 (in Japanese).

4) Nakabo T, Yamamoto S: Influence of kyphosis on chest wall motion-comparison of slump sitting and straight sitting-. Rigakuryouhoukagaku, 2009, 24: 697-701 (in Japanese)

5) Mabuchi S, Sasanuma N: Technique for improvement of thoracic motion and its notice points. J Phys Ther, 2003, 20: 945-952.

6) Yoshida T, Harada R, Maduchi Y, et al.: Influence of kyphosis posture on respiratory function. Annu Rep The Tohoku Sect Jpn Phys Ther Assoc, 2013, 25: $10-13$.

7) Kusakari Y, Sasaki M: Influence of kiphosis posture on cardiopulmonary response and exercise tolerance. Rigakuryouhoukagaku, 2003, 18: 187-191 (in Japanese).

8) Ito Y, Yamada T, Takeda M: Investigation of respiratory function and breathing pattern in elderly people with kyphosis posture. Rigakuryouhoukagaku, 2007, 22: 353-358 (in Japanese).

9) Sawaya Y, Ishizaka M, Kubo A, et al.: Correlation between skeletal muscle mass index and parameters of respiratory function and muscle strength in young healthy adults according to gender. J Phys Ther Sci, 2018, 30: 1424-1427. [Medline] [CrossRef]

10) Lorbergs AL, O'Connor GT, Zhou Y, et al.: Severity of kyphosis and decline in lung function: the Framingham study. J Gerontol A Biol Sci Med Sci, 2017, 72 : 689-694. [Medline]

11) Milne JS, Lauder IJ: Age effects in kyphosis and lordosis in adults. Ann Hum Biol, 1974, 1: 327-337. [Medline] [CrossRef]

12) Ettinger B, Black DM, Palermo L, et al.: Kyphosis in older women and its relation to back pain, disability and osteopenia: the study of osteoporotic fractures. Osteoporos Int, 1994, 4: 55-60. [Medline] [CrossRef]

13) Teragaki Y, Araya K, Sueki K, et al.: Reliability and validity of the index of kyphosis on sitting. Rigakuryouhoukagaku, 2004, 19: 137-140 (in Japanese).

14) Black LF, Hyatt RE: Maximal respiratory pressures: normal values and relationship to age and sex. Am Rev Respir Dis, 1969, 99: 696-702. [Medline]

15) Miller MR, Hankinson J, Brusasco V, et al. ATS/ERS Task Force: Standardisation of spirometry. Eur Respir J, 2005, 26: 319-338. [Medline] [CrossRef]

16) American Thoracic Society/European Respiratory Society: ATS/ERS Statement on respiratory muscle testing. Am J Respir Crit Care Med, 2002, 166: 518624. [Medline] [CrossRef]

17) Fujimoto S, Yoshida K, Sato S, et al.: Trunk and physiotherapy. Physical Therapy—Practice-Research·Education, 2013 , $20: 7-14$.

18) Sato M, Sato R, Sawaya Y, et al.: Relationships between spinal kyphosis and respiratory function among users of adult daycare rehabilitation services. Rigakuryouhoukagaku, 2019, 34: 461-465 (in Japanese).

19) Kasukawa Y, Miyakoshi N, Hongo M, et al.: Age-related changes in muscle strength and spinal kyphosis angles in an elderly Japanese population. Clin Interv Aging, 2017, 12: 413-420. [Medline] [CrossRef] 